\title{
Synthesis of a Novel Filtrate Reducer and Its Application in Water-Based Drilling Fluid for Ultra-High- Temperature Reservoirs
}

\author{
Dongyu Qiao, ${ }^{1,2}$ Zhongbin Ye $\mathbb{D}^{1,3}{ }^{1,3}$ Lei Tang, ${ }^{1}$ Yiping Zheng, ${ }^{2}$ Xindong Wang, \\ and Nanjun Lai ${ }^{1,3}$ \\ ${ }^{1}$ School of Chemistry and Chemical Engineering of Southwest Petroleum University, Chengdu, 610500 Sichuan, China \\ ${ }^{2}$ Engineer Technology Research Institute, CNPC Xibu Drilling Engineering Company Limited, Urumqi 830001, China \\ ${ }^{3}$ Oil \& Gas Field Applied Chemistry Key Laboratory of Sichuan Province, Chengdu, 610500 Sichuan, China
}

Correspondence should be addressed to Zhongbin Ye; yezb@swpu.edu.cn and Nanjun Lai; lainanjun@126.com

Received 11 September 2021; Accepted 1 October 2021; Published 29 October 2021

Academic Editor: Jinjie Wang

Copyright ( 2021 Dongyu Qiao et al. This is an open access article distributed under the Creative Commons Attribution License, which permits unrestricted use, distribution, and reproduction in any medium, provided the original work is properly cited.

\begin{abstract}
The high-temperature stability and filtration property controlling of ultra-high-temperature water-based drilling fluids is a worldwide problem. To resolve this problem, a high-temperature-resistant quaternary copolymer (HTRTP) was synthesized based on molecular structure optimization design and monomer optimization. The physical and chemical properties were characterized by infrared spectroscopy, thermal weight, and spectrophotometry, and their temperature and salt resistance was evaluated in different drilling fluids, combined with adsorption, particle size analysis, and stability test. The results show that the thermal stability of HTRTP is very strong, and the initial temperature of thermal decomposition is above $320^{\circ} \mathrm{C}$. The salt resistance of HTRTP is more than $162 \mathrm{~g} / \mathrm{L}$, and the calcium resistance is more than $5000 \mathrm{mg} / \mathrm{L}$, which is equivalent to the foreign temperature-resistant polymer DCL-a, and is superior to the domestic metal ion viscosity increasing fluid loss agent PMHA-II for drilling fluids. It has excellent high-temperature resistance $\left(245^{\circ} \mathrm{C}\right)$ and fluid loss reduction effect in fresh water base mud, fresh water weighted base mud, saturated brine base mud, and composite salt water base mud, which is better than foreign DCL-a $\left(245^{\circ} \mathrm{C}\right)$ and domestic PMHA $\left(220^{\circ} \mathrm{C}\right)$. The adsorption capacity of HTRTP on clay particles is large and firm, and the adsorption capacity changes little under the change of chemical environment and temperature. Both before and after HTRTP aging $\left(245^{\circ} \mathrm{C} / 16 \mathrm{~h}\right)$, the permeability of filter cake can be significantly reduced and its compressibility can be improved. By optimizing the particle size gradation of the drilling fluid and enhancing the colloid stability of the system, HTRTP can improve the filtration building capacity of the drilling fluid and reduce the filtration volume. The development of antithermal polymer provides a key treatment agent for the study of anti-high-temperature-resistant saline-based drilling fluid.
\end{abstract}

\section{Introduction}

The fluid loss additive, also known as the fluid loss control preparation and water loss additive, is an important drilling fluid treatment agent to ensure the stability of drilling fluid performance, reduce the loss of harmful fluids to the formation, stabilize the well wall, and ensure the well diameter rule $[1,2]$. At present, the following categories of fluid loss agents are used at home and abroad: (1) modified lignite [3]; (2) modified starch [4]; (3) modified cellulose [5]; (4) modified resin [6]; and (5) olefin monomer polymers [7]. With the development of the depth of petroleum exploration and development, the drilling depth keeps deepening and the bottom hole temperature is getting higher and higher, which puts forward higher requirements for the control of drilling fluid filtration and rheological properties [8,9]. Commonly used natural and natural modified fluid loss reducers could not meet the needs of deep and ultradeep well drilling. Polymer fluid loss additive not only reduces fluid loss but also regulates rheological properties $[10,11]$. It is an indispensable key treatment agent for high-temperature and ultrahigh-temperature water-based drilling fluids $[12,13]$. Since 
the 1970s, the new synthetic polymer drilling fluid treatment agent which is resistant to high temperature and electrolyte pollution has been studied at home and abroad and has been applied in deep and ultradeep well drilling [14, 15]. With excellent performance of resistance to high temperature and salt resistance, the treatment agent has the following several kinds: Oseh et al. [16] on synthesizing a polypropylene-silica nanocomposite ( $\left.\mathrm{PP}-\mathrm{SiO}_{2} \mathrm{NC}\right)$ using hot-emulsion sol-gel method as a viscosity modifier and filtration control agent for WBMs. $\mathrm{PP}-\mathrm{SiO}_{2} \mathrm{NC}$ is spherical, with a particle size distribution between 80 and $390 \mathrm{~nm}$, finely dispersed; a stronger resistance from $430^{\circ} \mathrm{C}$ to $485^{\circ} \mathrm{C}$; and better filtration control and rheological properties, and plastic viscosity is reduced by $22.7 \%$. Chang et al. [17] have developed a new environmentally friendly fluid loss agent nano-LS (nano-LS) with good thermal stability, salt tolerance, and calcium resistance. The water-based drilling fluid prepared with it maintains its stability at $200^{\circ} \mathrm{C}$ and can control the water loss at $7.5 \mathrm{~mL}$. The high-temperature- and saltresistant polymer DCL-a, developed by Philips and Chevron, can effectively reduce the high-temperature and highpressure filtration of drilling fluid. The temperature resistance is more than $230^{\circ} \mathrm{C}$, and it has strong salt and calcium resistance. At present, the thermal resistance of polymer filtrate reduction agents at home and abroad still cannot meet the requirements of ultra-high-temperature filtration control in deep and ultradeep well drilling $[18,19]$. Therefore, this paper carried out the synthesis and characterization of high-temperature- and salt-resistant quaternary polymer, evaluation of filtration loss performance and stability in drilling fluid, and analysis of its action mechanism [20, 21].

\section{Experimental}

2.1. Material. Anhydrous sodium carbonate, 2-methyl-2acrylamide propanesulfonic acid (AMPS), Nvinylpyrrolidone (NVP), N, N-diethylacrylamide (DEAM), and dimethyldiallylammonium chloride (DMDAAC) are all industrial products for the industrial pilot amplification production $[22,23]$. The initiator and sodium hydroxide were analytical pure. Drilling fluid with metal ions increased sticky fluid loss agent PMHA from the Xinjiang oil field (high-temperature-resistant polymer DCL-a, foreign ConocoPhillips company).

IRAffinity-1 Fourier Transform Infrared Spectrometer (Shimadzu Corporation, Japan), HTG-1 thermogravimetric analyzer (Beijing Hengjiu Scientific Instrument Factory), Model 722 UV-Vis Spectrophotometer (Shanghai Precision Instrument Co., Ltd.), ZNS2 medium pressure filter loss instrument (Qingdao Haitongda Special Instrument Co., Ltd.), and ZNN-D6 model six-speed rotary viscometer (Qingdao Haitongda Special Instrument Co., Ltd.) were the materials used.

\subsection{Synthesis of Quaternary Copolymer}

\subsubsection{Synthesis Principle}

(1) Competitive Rate of Polymer. The reactivity rate is the ratio of the rate constants of homopolymer (self) growth and copolymer (cross) growth. The reactivity ratios of the designed high-temperature-resistant quaternary copolymers can be estimated using the $-e$ equation proposed by Alfrey and Price. The calculated values of the reactivity ratios of the four monomers (Table 1) show that the product of the reactivity ratios between the monomers is less than 1 , indicating that the nonideal copolymerization occurs in this synthesis [24].

(2) Structural Formula. According to the principle of polymerization reaction, the possible structural formula of HTRTP is shown in Figure 1.

2.2.2. Synthesis. The reaction monomers (AMPS : DEAM : DMDAAC : NVP $=6: 3: 3: 1$ ) were added in the four-point flask, and then, the reaction monomers were added in turn. The $\mathrm{pH}$ value of the system was adjusted to 7.0 with $30 \% \mathrm{NaOH}$ solution, and the temperature was raised to $60^{\circ} \mathrm{C}$. The initiator of $0.1 \%$ of the total monomer was added, and the viscous liquid product was obtained by stirring for $4 \mathrm{~h}$. The product was dried and crushed at $105^{\circ} \mathrm{C}$ to obtain HTRTP in powder form.

\subsection{Characterization}

2.3.1. Composition and Molecular Weight. Acetone was used as precipitant, and HTRTP was purified and dried by solution precipitation. The structure of HTRTP was analyzed by Fourier transform infrared spectroscopy (FT-IR) with $\mathrm{KBr}$.

The "one-point method" was used to determine the intrinsic viscosity of the polymer (fluid loss additive), and the viscosity average molecular weight of the polymer was estimated by the Mark-Houwink empirical formula [25]. The calculation is as follows:

$$
M=\sqrt[a]{\frac{\sqrt{2\left[\left(\left(\tau / \tau_{0}\right)-1\right)-\ln \left(\tau / \tau_{0}\right)\right]}}{k c}},
$$

where $C$ is solute concentration, $\mathrm{g} / \mathrm{mL} ; M$ is the molecular weight of the solute; and $K$ and $\alpha$ are constants related to the determination conditions and polymer structure, and the value of $K$ is $3.684 \times 10^{-2}$, and the value of $\alpha$ is 0.646 .

2.3.2. Resistance to Temperature. In $\mathrm{N}_{2}$ atmosphere, the purified HTRTP was subjected to thermogravimetric analysis on a thermogravimetric analyzer at a temperature of $29^{\circ} \mathrm{C}-800^{\circ} \mathrm{C}$ and a heating rate of $5^{\circ} \mathrm{C} / \mathrm{min}$ [26].

With $0.2 \mathrm{~mol} / \mathrm{L} \mathrm{NaCl}$ solution as solvent, $0.2 \%$ HTRTP and DCL-a solutions were prepared, and their intrinsic viscosities after aging at different temperatures for 8 hours were measured by an ohmmeter.

2.3.3. Ability to Antisalt. The salting-out resistance of hightemperature-resistant quaternary copolymer was tested and evaluated by UV-visible photometry [27]. In making polymer aqueous solution (PMHA, DCL-a, and HTRTP), the concentration is $0.5 \%$. Add different amounts of distilled water and $180 \mathrm{~g} / \mathrm{L}$ sodium chloride solution to a test tube 
TABLE 1: Estimation results of monomer's reactivity ratio.

\begin{tabular}{lcccc}
\hline Monomer & $Q$ value & $e$ value & Competitive rate of poly & Competitive rate product \\
\hline NVP & 0.15 & -1.2 & $r_{12}=0.05 ; r_{13}=0.008 ; r_{14}=0.002$ & $r_{12} r_{21}=0.059$ \\
AMPS & 0.38 & 0.46 & $r_{21}=1.180 ; r_{23}=0.487 ; r_{24}=0.096$ & $r_{13} r_{31}=0.002$ \\
DEAM & 1.16 & 1.32 & $r_{31}=0.278 ; r_{32}=0.981 ; r_{34}=0.174$ & $r_{14} r_{41}=0.005$ \\
DMDACC & 5.46 & 1.17 & $r_{41}=2.274 ; r_{42}=6.261 ; r_{43}=5.61$ & $r_{24} r_{32}=0.478$ \\
& & & & $r_{34} r_{43}=0.601$ \\
\hline
\end{tabular}

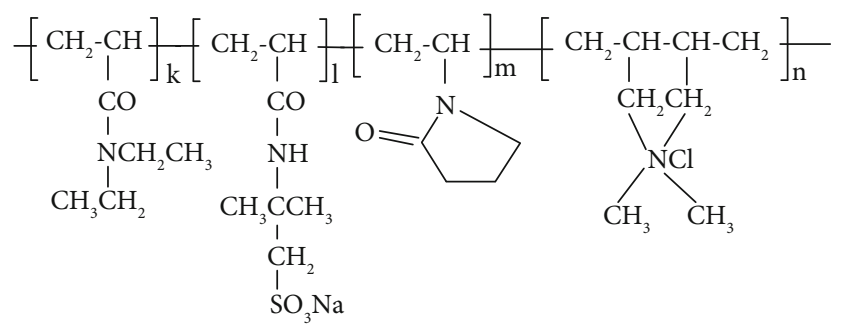

FIGURE 1

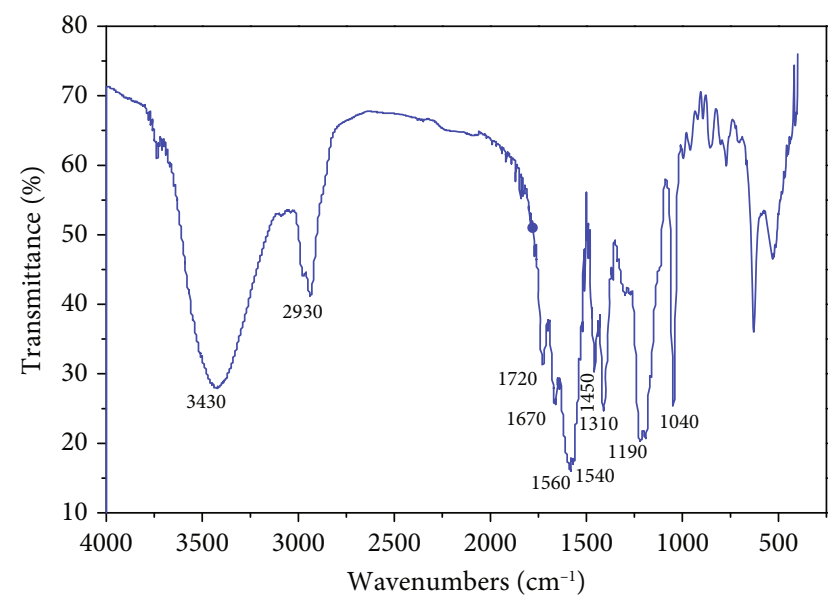

Figure 2: Infrared spectrogram of HTRTP.

containing $1.0 \mathrm{~mL}$ sample solution, and shake well. Distilled water was used as blank experiment, and the transmissivity of each solution was measured with a 722 spectrophotometer. After salting out, the solution becomes turbid, which causes the change of transmission ratio of the solution. Therefore, when the salt in the solution reaches or exceeds the turbidity point, the transmission ratio of the solution is significantly reduced, and the turbidity point salinity of the copolymer is determined.

\subsection{Evaluation of Filtration Loss Reduction Effect}

2.4.1. Evaluation of Fluid Loss Reduction Effect in Fresh Water Base Slurry. The experimental base slurry is composed of $400 \mathrm{~mL}$ tap water $+0.8 \mathrm{~g}$ anhydrous sodium carbonate $+4 \%$ secondary bentonite $+3 \%$ evaluation soil, respectively, to the early hydration good base paste to add $1 \%$ of the sample evaluation (PMHA, DCL-a, and HTRTP), stirring evenly, measuring the rheological property and filtration [28]. The experimental slurry was then put into a high-temperature aging tank and rolled at $220^{\circ} \mathrm{C}$ and $245^{\circ} \mathrm{C}$ for $16 \mathrm{~h}$, respectively. The rheological properties and filtration loss of the slurry were measured by the same method.

2.4.2. Effect of Fluid Loss Reduction in Fresh Water Weighted Base Slurry. The experimental base slurry is composed of $400 \mathrm{~mL}$ tap water $+1.2 \mathrm{~g}$ anhydrous sodium carbonate +6 \%secondary bentonite $+5 \%$ evaluation soil $+30 \%$ barite, respectively, to the early hydration good base paste to add $1 \%$ of the sample evaluation (PMHA, DCL-a, HTRTP), stirring evenly, into the high-temperature aging tank, respectively, under $220^{\circ} \mathrm{C}$ and $245^{\circ} \mathrm{C}$ hot rolled out after $16 \mathrm{~h}$, measuring the rheological property and filtration.

2.4.3. Effect of Fluid Loss Reduction in Saturated Salt-WaterBased Slurry. The experimental base slurry is composed of-

$400 \mathrm{~mL}$ tap water $+1.2 \mathrm{~g}$ anhydrous sodium carbonate $+6 \%$ secondary bentonite $+10 \%$ evaluation soil $+30 \%$ sodium chloride, respectively, to the early hydration good base paste to add $1.5 \%$ of the sample evaluation (PMHA, DCL-a, HTRTP), stirring evenly, into the high-temperature aging tank, respectively, under $220^{\circ} \mathrm{C}$ and $245^{\circ} \mathrm{C}$ hot rolled out after $16 \mathrm{~h}$, measuring the rheological property and filtration.

\subsection{Research on Mechanism of Action}

2.5.1. Adsorption Characteristics on Clay Particle Surface. A known amount of polymer solution was added to $4 \mathrm{wt} \% \mathrm{cal}$ cium montmorillonite (purified with 15 wt $\% \mathrm{H}_{2} \mathrm{O}_{2}$ ) suspension and then diluted with $50 \mathrm{~mL}$ distilled water. The initial concentration of polymer was recorded as $c_{0}$. The suspension was agitated vigorously and then left to stand for $20 \mathrm{~min}$ to allow the adsorption process of the quadripolymer to complete at given temperature. The suspension was subsequently centrifuged for $30 \mathrm{~min}$ at a speed of $1000 \mathrm{rpm}$ using a KUBOTA 3500 centrifuge. The concentration of unadsorbed quadripolymer, $c_{1}$, located in the clear centrifuged supernatant was measured via absorbance at wavelengths of $390 \mathrm{~nm}$ and $330 \mathrm{~nm}$ for polymer solution using an ultraviolet spectrophotometer (722, Shanghai Yuanxi Instruments Co., Ltd., China). Applying material balance of the polymer, the adsorption of polymer on clay particles can be calculated via

$$
\tau=\frac{v\left(c_{0}-c_{1}\right)}{G},
$$


TABLE 2: Testing results of intrinsic viscosity and molecular weights.

\begin{tabular}{lcccccc}
\hline Sample & Concentration $(\mathrm{g} / 100 \mathrm{~mL})$ & 0.1 & 0.2 & 0.3 & Average intrinsic viscosity $(\mathrm{mL} / \mathrm{g})$ & Molecular weight \\
\hline \multirow{2}{*}{ HTRTP } & Average outflow time $(\mathrm{s})$ & 76.13 & 98.68 & 123.24 & 284.06 & 1040322 \\
& Intrinsic viscosity $(\mathrm{mL} / \mathrm{g})$ & 279.06 & 288.29 & 284.87 & & \multirow{2}{*}{139.78} \\
\multirow{2}{*}{ DCL-a } & Average outflow time/s & 79.92 & 107.69 & 141.06 & 372721 \\
& Intrinsic viscosity $(\mathrm{mL} / \mathrm{g})$ & 332.72 & 341.59 & 345.04 & \\
\hline
\end{tabular}

where $\tau$ is the mass of polymers absorbed onto specific weight calcium montmorillonite, $\mathrm{mg} / \mathrm{g}$; $v$ is volume of solution, $\mathrm{L} ; c_{0}$ and $c_{1}$ are polymer concentration before and after polymer absorbed onto calcium montmorillonite, $\mathrm{mg} / \mathrm{L}$; and $G$ is the mass of calcium montmorillonite, $g$.

2.5.2. Influence on Filter Cake Quality. The effect of its addition in fresh water base slurry on the permeability of filter cake was investigated. After measuring the API filtration loss, carefully remove the substrate slurry on the surface of the filter cake [29], replace it with distilled water, measure the volume of water for $30 \mathrm{~min}$, measure the thickness of the filter cake with a steel plate ruler, and calculate the permeability $K$ of the filter cake according to the following formula:

$$
K=0.175 v h \times 10^{-6},
$$

where $K$ is the permeability of mud cake, $\mu \mathrm{m}^{2} ; v$ is the effluent volume, $\mathrm{mL}$; $h$ is the thickness of mud cake, $\mathrm{mm}$; and 0.175 is the conversion factor ( 0.07 for high temperature and high pressure).

The effect of several treatment agents on the compressibility of base mud was investigated by using the "twostage water loss method" which is simple, feasible, and reliable. If other factors are set to be constant, the compressibility of filter cake can be expressed by a simple proportional relationship of filtration rate at 500 psi and 100 psi:

$$
R=\frac{V_{500}}{V_{100}},
$$

in which $R$ is the compressibility coefficient of the filter cake and $V_{500}$ and $V_{100}$ are static filtration loss under pressure difference of 500 psi and 100 psi, respectively.

2.5.3. Particle Size and Specific Area Measurements of Calcium Clay. The suspensions were prepared by mixing deionized water, $4 \%(w / v)$ calcium montmorillonite, and $0.3 \%(w / v)$ viscosity breaker (XY-28, sulfonated tannin and quadripolymer separately), stirring for 20 minutes at a high speed of 10,000 rpm and aging for 24 hours at room temperature. Aging experiments of suspensions were carried out in a XGRL-4A-type rolling oven through hot rolling at $220^{\circ} \mathrm{C}$ (XY-28) or $245^{\circ} \mathrm{C}$ (sulfonated tannin and quadripolymer) for 16 hours. Concentrated $\mathrm{NaOH}(10 \mathrm{~mol} / \mathrm{L})$ and $\mathrm{HCl}$ $(6 \mathrm{~mol} / \mathrm{L})$ solutions were used to change $\mathrm{pH}$ so as not to cause excessive dilution of samples. The size distribution and specific area of clay particles in suspension were determined using a Bettersize2000 laser particle analyzer.

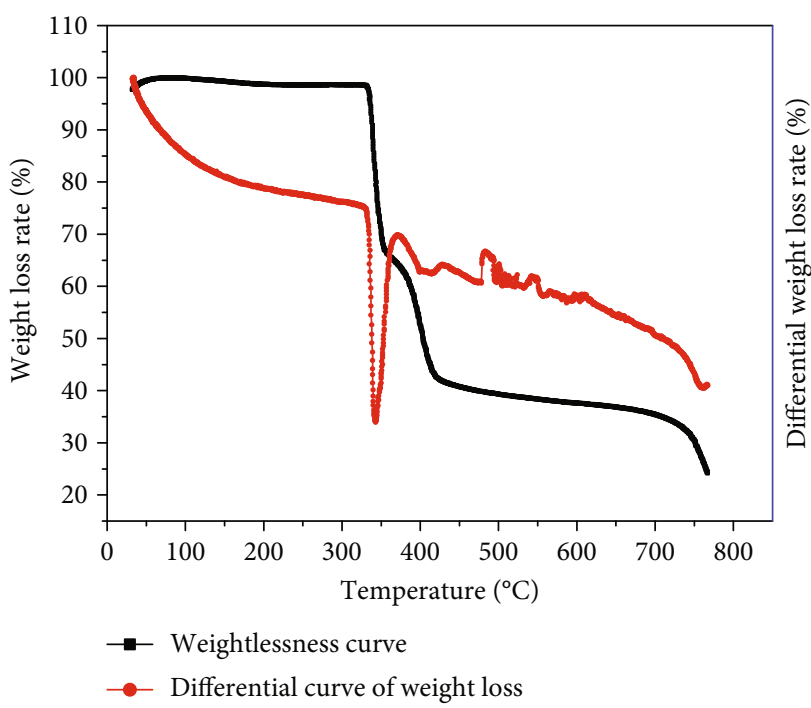

FIgURe 3: Curves of TG and DTA of HTRTP in nitrogen gas ambience.

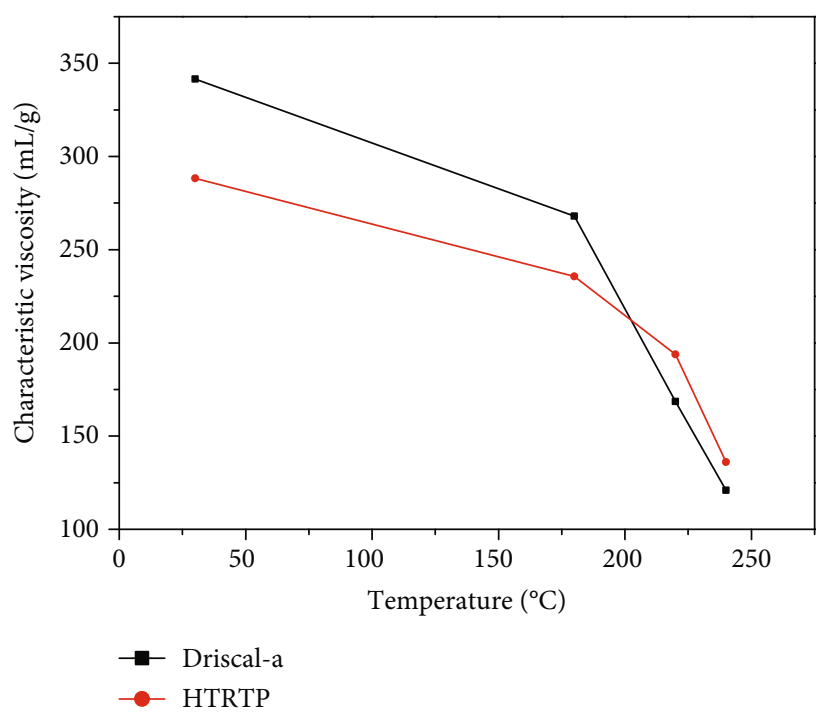

FIgURE 4: Viscosity-temperature curves of HTRTP and DCL-a.

2.5.4. Influence on Stability of Fresh Water Base Slurry Colloid. Turbiscan, an infrared scanning dynamic stability tester, can quantitatively evaluate the stability of dispersion systems such as colloid, foam, and suspension. The effects of $0.1 \%, 0.2 \%$, and $0.3 \%$ HTRTP on the colloidal stability of $3 \%$ bentonite slurry before and after aging $\left(245^{\circ} \mathrm{C} / 16 \mathrm{~h}\right)$ were investigated. 
TABLE 3: Experimental results of antisalting out of PMHA.

\begin{tabular}{lcccccc}
\hline Concentration of $\mathrm{Cl}^{-}(\mathrm{g} / \mathrm{L})$ & 0 & 90 & 108 & 126 & 144 & 162 \\
\hline Solution transmission ratio of PMHA & 98.8 & 98.6 & 98.3 & 97.9 & 95.1 & 94.3 \\
Solution transmission ratio of DCL-a & 99.0 & 98.9 & 98.7 & 98.5 & 98.3 & 98.0 \\
Solution transmission ratio of HTRTP & 98.3 & 98.2 & 98.1 & 98.0 & 97.7 \\
\hline
\end{tabular}

TABLE 4: Experimental results of antisalting out of PMHA.

\begin{tabular}{lcccccc}
\hline Concentration of $\mathrm{CaCl}_{2}(\mathrm{mg} / \mathrm{L})$ & 0 & 500 & 1500 & 2500 & 4000 & 5000 \\
\hline Solution transmission ratio of PMHA & 98.8 & 98.4 & 98.0 & 96.2 & 95.4 & 94.5 \\
Solution transmission ratio of DCL-a & 99.0 & 99.0 & 98.8 & 98.6 & 98.4 & 98.1 \\
Solution transmission ratio of HTRTP & 98.3 & 98.2 & 98.1 & 98.0 & 97.8 \\
\hline
\end{tabular}

TABLE 5: Comparison of fluid loss controlling of fluid loss agents in fresh water slurry.

\begin{tabular}{|c|c|c|c|c|c|}
\hline Experimental slurry & Test conditions & $\mathrm{AV}(\mathrm{mPa} \cdot \mathrm{s})$ & $\mathrm{PV}(\mathrm{mPa} \cdot \mathrm{s})$ & $\mathrm{YP}(\mathrm{Pa})$ & API $(\mathrm{mL})$ \\
\hline \multirow{3}{*}{ 3-1 basic slurry } & Room temperature & 8.5 & 3 & 5.5 & 24.0 \\
\hline & Room temperature after $220^{\circ} \mathrm{C} / 16 \mathrm{~h}$ & 7 & 3 & 4 & 34.0 \\
\hline & Room temperature after $245^{\circ} \mathrm{C} / 16 \mathrm{~h}$ & 8.5 & 8 & 0.5 & 41.0 \\
\hline \multirow{2}{*}{ Basic slurry + 1\%PMHA } & Room temperature & 60 & 30 & 30 & 8.4 \\
\hline & Room temperature after $220^{\circ} \mathrm{C} / 16 \mathrm{~h}$ & 4 & 1 & 3 & 12.4 \\
\hline \multirow{2}{*}{ Basic slurry $+1 \% D C L-a$} & Room temperature & 53 & 21 & 32 & 10.6 \\
\hline & Room temperature after $245^{\circ} \mathrm{C} / 16 \mathrm{~h}$ & 11 & 10 & 1 & 20.6 \\
\hline \multirow{2}{*}{ Basic slurry + 1\%HTRTP } & Room temperature & 40 & 28 & 12 & 7.8 \\
\hline & Room temperature after $245^{\circ} \mathrm{C} / 16 \mathrm{~h}$ & 17 & 14 & 3 & 11.0 \\
\hline
\end{tabular}

TABLE 6: Comparison of fluid loss controlling of fluid loss agents in weighted fresh water slurry.

\begin{tabular}{|c|c|c|c|c|c|}
\hline Experimental slurry & Test conditions & $\mathrm{AV}(\mathrm{mPa} \cdot \mathrm{s})$ & $\mathrm{PV}(\mathrm{mPa} \cdot \mathrm{s})$ & $\mathrm{YP}(\mathrm{Pa})$ & $\mathrm{API}(\mathrm{mL})$ \\
\hline \multirow{2}{*}{ 3-2 basic slurry } & Room temperature after $220^{\circ} \mathrm{C} / 16 \mathrm{~h}$ & 35 & 16 & 19 & 16.0 \\
\hline & Room temperature after $245^{\circ} \mathrm{C} / 16 \mathrm{~h}$ & 38 & 26 & 12 & 21.0 \\
\hline 1\% PMHA & Room temperature after $220^{\circ} \mathrm{C} / 16 \mathrm{~h}$ & 33.5 & 27 & 6.5 & 8.4 \\
\hline $1 \% \mathrm{DCL}-\mathrm{a}$ & Room temperature after $245^{\circ} \mathrm{C} / 16 \mathrm{~h}$ & 45 & 35 & 10 & 6.6 \\
\hline 1\% HTRTP & Room temperature after $245^{\circ} \mathrm{C} / 16 \mathrm{~h}$ & 41 & 32 & 9 & 6.0 \\
\hline
\end{tabular}

TABLE 7: Comparison of fluid loss controlling of fluid loss agents in saturated brine slurry.

\begin{tabular}{|c|c|c|c|c|c|}
\hline Experimental slurry & Test conditions & $\mathrm{AV}(\mathrm{mPa} \cdot \mathrm{s})$ & $\mathrm{PV}(\mathrm{mPa} \cdot \mathrm{s})$ & $\mathrm{YP}(\mathrm{Pa})$ & $\mathrm{API}(\mathrm{mL})$ \\
\hline \multirow{2}{*}{ Basic slurry } & Room temperature after $220^{\circ} \mathrm{C} / 16 \mathrm{~h}$ & 18 & 8 & 10 & 124 \\
\hline & Room temperature after $245^{\circ} \mathrm{C} / 16 \mathrm{~h}$ & 17.5 & 6 & 11.5 & 143 \\
\hline 1.5\% РMHA & Room temperature after $220^{\circ} \mathrm{C} / 16 \mathrm{~h}$ & 16.5 & 9 & 7.5 & 49 \\
\hline $1.5 \% \mathrm{DCL}-\mathrm{a}$ & Room temperature after $245^{\circ} \mathrm{C} / 16 \mathrm{~h}$ & 40 & 19 & 21 & 24 \\
\hline 1.5\% HTRTP & Room temperature after $245^{\circ} \mathrm{C} / 16 \mathrm{~h}$ & 45 & 24 & 21 & 18 \\
\hline
\end{tabular}

\section{Results and Discussion}

\subsection{Characterization}

3.1.1. Composition and Molecular Weight. It can be seen from Figure 2 that the stretching vibration absorption peak at $3450 \mathrm{~cm}^{-1}$ is $\mathrm{N}-\mathrm{H} ; 3060 \mathrm{~cm}^{-1}$ is the absorption peak of stretching vibration of $\mathrm{C}-\mathrm{H}$ bond of $-\mathrm{CH}_{2}$ - in the ring. $2960 \mathrm{~cm}^{-1}$ is the characteristic absorption peak of C-H bond of $-\mathrm{CH}_{3} .2920 \mathrm{~cm}^{-1}$ is the absorption peak of stretching vibration of $\mathrm{C}-\mathrm{H}$ bond of $-\mathrm{CH}_{2}$ in chain. At $1730 \mathrm{~cm}^{-1}$, there is a stretching vibration absorption peak with $\mathrm{C}=\mathrm{O}$. The characteristic absorption peaks of $-\mathrm{C}(\mathrm{O}) \mathrm{NH}$ - are at $1660 \mathrm{~cm}^{-1}$ and $1540 \mathrm{~cm}^{-1}$. At $1520 \mathrm{~cm}^{-1}$, there is the vibration absorption peak of $\mathrm{N}-\mathrm{H}$ bond deformation. The absorption peak of bending vibration of $\mathrm{C}-\mathrm{H}$ bond of $-\mathrm{CH}_{2}$ is at $1460 \mathrm{~cm}^{-1}$. At $1300 \mathrm{~cm}^{-1},=\mathrm{C}=\mathrm{N}$ - stretching vibration absorption peaks. The characteristic absorption peaks of$\mathrm{SO}_{3}{ }^{-}$are at $1190 \mathrm{~cm}^{-1}$ and $1040 \mathrm{~cm}^{-1}$. The results show that 


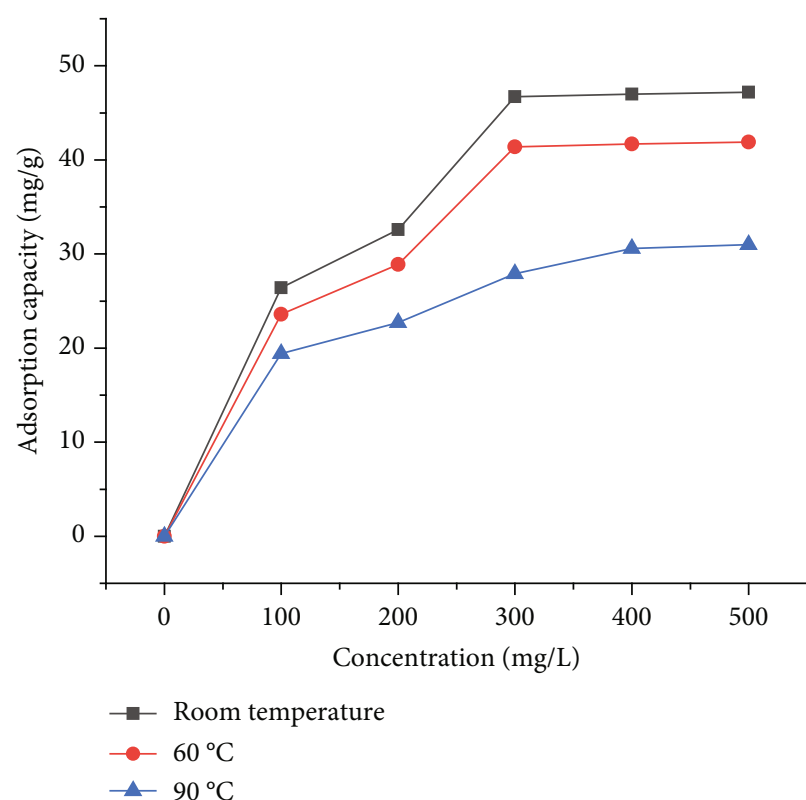

(a) HTRTP

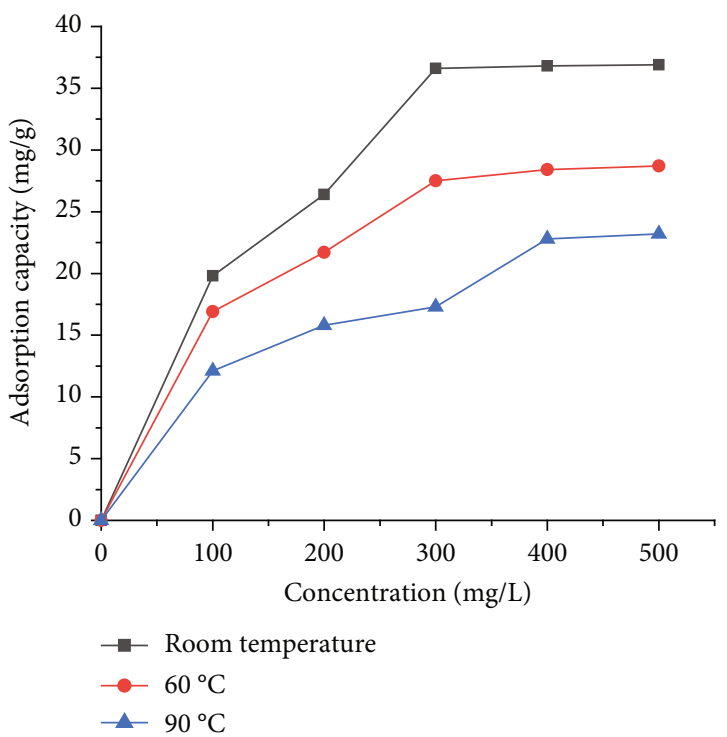

(b) DCL-a

FIGURE 5: Effect of temperature on adsorption quantity of DCL-a and HTRTP.

the molecular chain of the product has the predicted group of molecular structure design, which verifies the correctness of the molecular structure design and the correctness of the HTRTP synthesis reaction scheme.

It can be seen from the test results in Table 2 that the molecular weight of HTRTP is about 1.04 million, which is smaller than that of high-temperature-resistant polymer DCL-a, and its influence on drilling fluid viscosity will be smaller than that of DCL-a.

3.1.2. Temperature Resistance. It can be seen from the thermal difference curve in Figure 3 that the thermal decomposition process of HTRTP can be divided into many stages, of which there are two main pyrolysis stages. The first stage occurs between 320 and $360^{\circ} \mathrm{C}$ with a weight loss rate of $20 \%-25 \%$, which is mainly the decomposition of carboxylic acid group 9 and sulfonic acid group on the side chain. The second stage, which occurs above $400^{\circ} \mathrm{C}$, is mainly the decomposition of the backbone chain of polymerization. The total weight loss rate of these two stages is $52.41 \%$. It can be seen that the high-temperature-resistant quaternary copolymer HTRTP has strong thermal stability.

As shown in Figure 4, with the increase of aging temperature, the intrinsic viscosity of HTRTP decreased more slowly than that of DCL-a, indicating that HTRTP had better temperature resistance than DCL-a in aqueous solution.

3.1.3. Resistance to Salting Out. It can be seen from Table 3 that when the $\mathrm{Cl}^{-}$concentration of PMHA increases from $126 \mathrm{~g} / \mathrm{L}$ to $144 \mathrm{~g} / \mathrm{L}$, the transmittance of PMHA solution changes suddenly, indicating that the solution begins to become cloudy; that is, the antisalting out ability of PMHA (calculated by $\mathrm{Cl}^{-}$) is between $126 \mathrm{~g} / \mathrm{L}$ and $144 \mathrm{~g} / \mathrm{L}$. At the $\mathrm{Cl}^{-}$concentration of $162 \mathrm{~g} / \mathrm{L}$, the transmittance of DCL-a

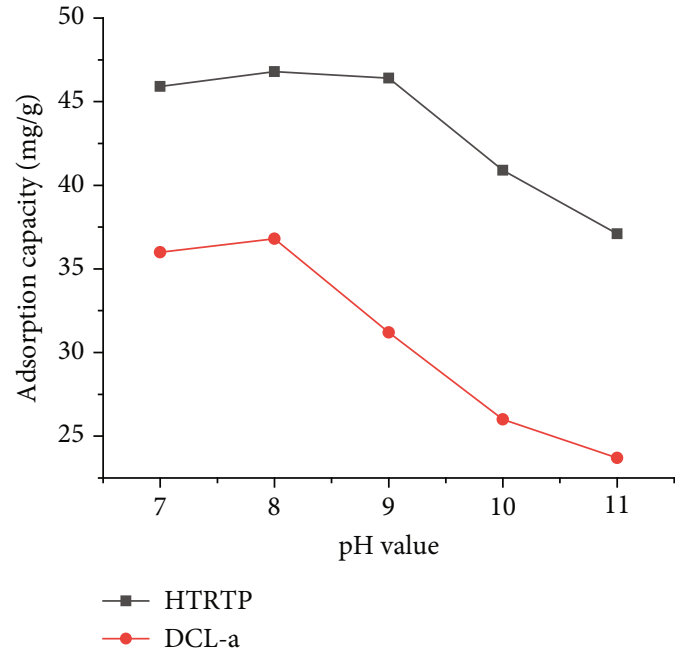

FIgURE 6: Effect of $\mathrm{pH}$ value on adsorption quantity of DCL-a and HTRTP.

solution and HTRTP solution still has no obvious change, indicating that the solutions have not become turbid; that is, the salting-out resistance of DCL-a and HTRTP (calculated by $\mathrm{Cl}^{-}$) is greater than $162 \mathrm{~g} / \mathrm{L}$.

It can be seen from Table 4 that when the concentration of $\mathrm{CaCl}_{2}$ increases from $1500 \mathrm{mg} / \mathrm{L}$ to $2500 \mathrm{mg} / \mathrm{L}$, the transmittance of PMHA solution changes suddenly, indicating that the solution begins to become cloudy; that is, the calcium resistance of PMHA (calculated by $\mathrm{CaCl}_{2}$ ) is between $1500 \mathrm{mg} / \mathrm{L}$ and $2500 \mathrm{mg} / \mathrm{L}$; with the increase of $\mathrm{CaCl}_{2}$ concentration, the transmittance of DCL-a solution and HTRTP solution has no significant change. When $\mathrm{CaCl}_{2}$ concentration reached $5000 \mathrm{mg} / \mathrm{L}$, the transmittance did not change 
obviously, which indicated that the solutions did not become turbid; that is, the calcium resistance of DCL-a and HTRTP (calculated by $\mathrm{CaCl}_{2}$ ) was greater than $5000 \mathrm{mg} / \mathrm{L}$.

\subsection{Evaluation of Fluid Loss Reduction Effect}

3.2.1. Evaluation of Fluid Loss Reduction in Fresh Water Base Slurry. As shown in Table 5, the API filtration loss of HTRTP was the lowest before and after aging, and the viscosity changed the least before and after aging. The filtration loss of fresh water base slurry treated with 1\% HTRTP decreased from $41 \mathrm{~mL}$ to $11 \mathrm{~mL}$ after aging at $245^{\circ} \mathrm{C} / 16 \mathrm{~h}$ at high temperature. 1\% PMHA was processed in fresh water slurry in $220^{\circ} \mathrm{C} / 16 \mathrm{~h}$ after high-temperature aging filtration quantity from $34 \mathrm{~mL}$ of $12.4 \mathrm{~mL}$, but after aging experiment, paste viscosity decreased; treatment may have serious degradation. When the fresh water base slurry treated with $1 \%$ DCL-a was aged at $245^{\circ} \mathrm{C} / 16 \mathrm{~h}$, the filtrate loss reduction effect was not as good as that of HTRTP. The results indicated that HTRTP not only had a good filtration loss reduction effect but also had a better temperature resistance in fresh water base slurry.

3.2.2. Effect of Fluid Loss Reduction in Fresh Water Weighted Base Slurry. As can be seen from Table 6, API filtration loss of experimental slurry after aging is low, among which the experimental slurry treated by $1 \%$ HTRTP has the lowest filtration loss, which is $6.0 \mathrm{~mL}$. It was shown that in fresh water increased base slurry, HTRTP fluid loss effect is better than PMHA and DCL-a.

\subsubsection{Effect of Fluid Loss Reduction in Saturated Salt-Water-} Based Slurry. It can be seen from Table 7 that, compared with the base slurry, the API filtration loss of the aging experimental slurry treated with filtration reduction agent was significantly reduced, among which the experimental slurry treated with 1.5\% HTRTP had the lowest filtration loss, which was $18.0 \mathrm{~mL}$. It is shown that the filtration reduction effect of HTRTP is better than that of PMHA and DCLa in saturated salt-water-based slurry.

\subsection{Study on Mechanism of Action}

\subsubsection{Adsorption Properties on the Surface of Clay Particles}

(1) Influence of Temperature. As can be seen from Figure 5, at the same temperature, with the increase of HTRTP and DCL-a concentration, their adsorption capacity on clay particles increased. With the increase of temperature, the adsorption amount decreased. It can also be seen from the figure that both HTRTP and DCL-a have different adsorption isotherms at different temperatures. The reason is that adsorption is an exothermic reaction, and increasing temperature is conducive to equilibrium in the direction of desorption. In addition, when the temperature rises, the thermal movement of clay particles intensifies, which is not conducive to adsorption.

(2) Influence of $\mathrm{pH}$. As can be seen from Figure 6, when $\mathrm{pH}$ is 8 , the adsorption capacity of the two polymers on the surface of clay particles reaches the maximum. When $\mathrm{pH}$

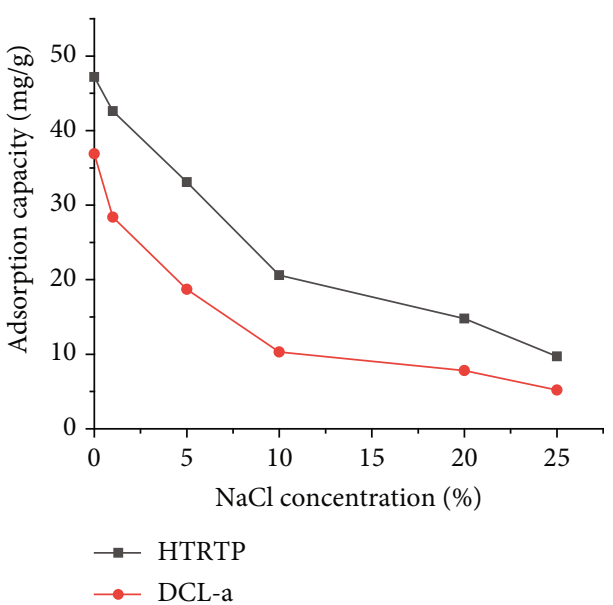

Figure 7: Effect of $\mathrm{NaCl}$ content on adsorption quantity of DCL-a and HTRTP.

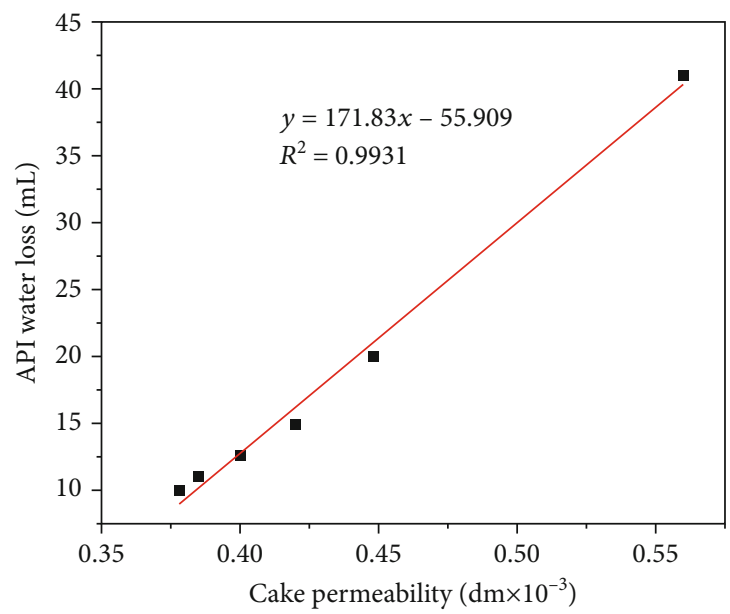

FIgURE 8: Relation between filter cake permeability and API filtration under different HTRTP contents.

is higher or lower than this value, the adsorption capacity decreases. Within the test range, the higher the $\mathrm{pH}$ value, the lower the adsorption capacity. The reason is that when the $\mathrm{pH}$ is 8 , the clay particles are fully dispersed and the negative charge on the surface of the particles is moderate. When $\mathrm{pH}$ becomes lower, it is not conducive to the full dispersion of clay particles, which can be used for adsorption of small surface area; when the $\mathrm{pH}$ value is higher than this value, more $\mathrm{OH}^{-}$is adsorbed on the surface of clay particles, which further enhances the electronegativity of the surface. The electrostatic action is not conducive to the adsorption of polymer molecules. As can be seen from the figure, not only is the adsorption capacity of HTRTP greater than that of DCL-a, but with the increase of $\mathrm{pH}$, the adsorption capacity of HTRTP on the surface of clay particles decreases more slowly than that of DCL-a. This is because certain cationic groups are introduced into HTRTP molecules, which can weaken the influence of the increase of electronegativity on the surface of clay particles on adsorption. 
TABLE 8: Test results of filter cake compressibility.

\begin{tabular}{|c|c|c|c|c|}
\hline Formula & Test conditions & $V_{100}(\mathrm{~mL})$ & $V_{500}(\mathrm{~mL})$ & $R$ \\
\hline \multirow{3}{*}{ Basic slurry: $4 \%$ bentonite $+3 \%$ evaluation of soil } & Room temperature & 22 & 43 & 1.95 \\
\hline & Room temperature after $220^{\circ} \mathrm{C} / 16 \mathrm{~h}$ & 34 & 72 & 2.12 \\
\hline & Room temperature after $245^{\circ} \mathrm{C} / 16 \mathrm{~h}$ & 42 & 90 & 2.14 \\
\hline \multirow{2}{*}{ Basic slurry + 1\% PMHA } & Room temperature & 8.6 & 16 & 1.86 \\
\hline & Room temperature after $220^{\circ} \mathrm{C} / 16 \mathrm{~h}$ & 12 & 23.4 & 1.95 \\
\hline \multirow{2}{*}{ Basic slurry $+1 \% \mathrm{DCL}-\mathrm{a}$} & Room temperature & 12 & 21 & 1.75 \\
\hline & Room temperature after $245^{\circ} \mathrm{C} / 16 \mathrm{~h}$ & 20 & 36 & 1.80 \\
\hline \multirow{2}{*}{ Basic slurry + 1\%HTRTP } & Room temperature & 8 & 12.8 & 1.60 \\
\hline & Room temperature after $245^{\circ} \mathrm{C} / 16 \mathrm{~h}$ & 11.6 & 19 & 1.64 \\
\hline
\end{tabular}

(3) Effect of Sodium Chloride Addition on Adsorption Capacity. It can be seen from Figure 7 that with the increase of sodium chloride dosage, the adsorption amount of HTRTP and DCL-a on clay particles decreases. This is because, after adding sodium chloride, a large amount of $\mathrm{Na}^{+}$accumulates near clay particles, compressing their diffusion electric double layer; the $\zeta$ potential decreases; the repulsive force weakens; the agglomeration of clay particles increases; and the surface area decreases. In addition, the addition of sodium chloride affects the extension of polymer molecular chain, which is not conducive to adsorption. Therefore, in sodium chloride brine drilling fluids, the contribution of polymer plugging and improving filtrate viscosity to fluid loss reduction performance is increased.

3.3.2. Influence on the Quality of Filter Cake. It can be seen from Figure 8 that there is a good linear relationship between filter cake permeability and API filtration amount. With the increase of HTRTP addition, API filtration amount decreases before and after experimental slurry aging, and the permeability of filter cake also decreases.

It can be seen from Table 8 that the compressibility coefficient of the experimental slurry before aging is lower than that after aging, indicating that high temperature will cause the compressibility reduction of the drilling fluid filter cake. The compression coefficient of experimental slurry with filtrate loss additive before and after aging is lower than that of base slurry, which indicates that improving the compressibility of filter cake is also one of the action mechanisms of filtrate loss additive. The filter cake added with HTRTP slurry has the lowest compressibility coefficient, which is consistent with the best filtration loss reduction effect.

3.3.3. Effect on Particle Size Distribution of Fresh Water Base Slurry. As can be seen from Figure 9, after aging, the proportion of particles with smaller particle size in the experimental slurry decreases, while the content of particles with larger particle size increases; both particle size and distribution become larger, which is one of the reasons for the increase of filtration loss after aging. The mean particle size of different suspensions was $1.7 \mu \mathrm{m}, 21.5 \mu \mathrm{m}, 7.5 \mu \mathrm{m}$, and $17.6 \mu \mathrm{m}$, respectively (tagged in Figure 9). After adding HTRTP, both before and after aging, the particle size distribution of exper-

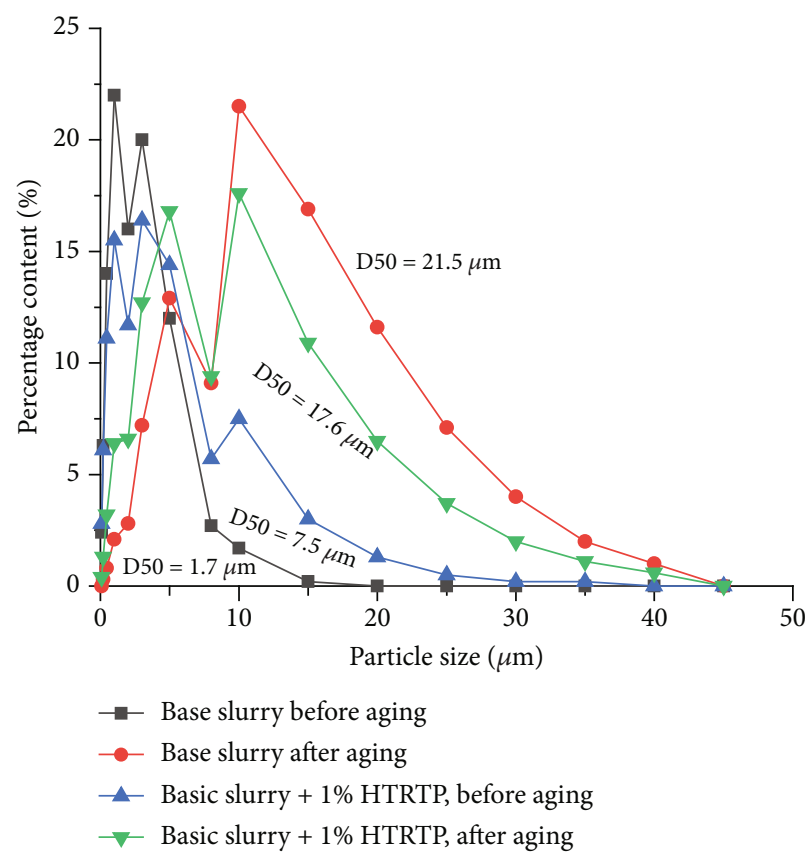

FIGURE 9: Test results of particle size distribution.

imental slurry is wider and the grading is more reasonable, so the filtration loss of experimental slurry is reduced.

3.3.4. Effect on Stability of Fresh Water Base Slurry Colloids. As can be seen from Figure 10, the colloidal stability of the experimental slurry was significantly better than that of the base slurry after the addition of HTRTP, and the colloidal stability of the experimental slurry increased with the increase of the amount of HTRTP. After aging at $245^{\circ} \mathrm{C} / 16 \mathrm{~h}$, high temperature promoted the hydration and dispersion of bentonite. In the experiment, it was measured that the thickness of the upper "clear liquid" of the aging base slurry was $0.30 \mathrm{~mm}$ after standing for $24 \mathrm{~h}, 0.1 \mathrm{~mm}$ when adding $0.1 \%$ HTRTP, $0.06 \mathrm{~mm}$ when adding $0.2 \%$ HTRTP, and $0.04 \mathrm{~mm}$ when adding $0.3 \%$ HTRTP. Combined with the previous particle size test results, it can be seen that for the base slurry with low bentonite content, the contribution of adhesive protection of HTRTP to filtration loss reduction is greater than that after aging. After aging, the mechanism 

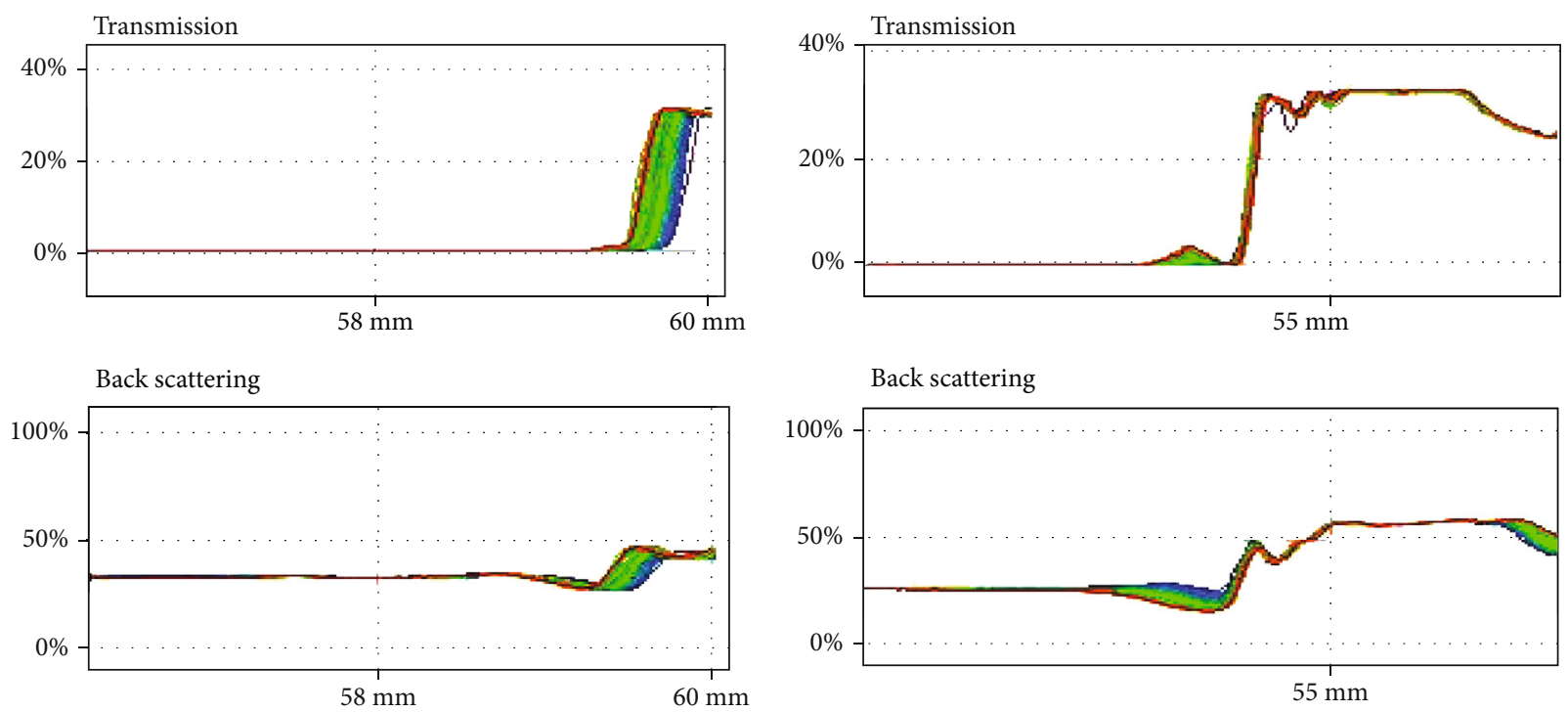

(a) Slurry
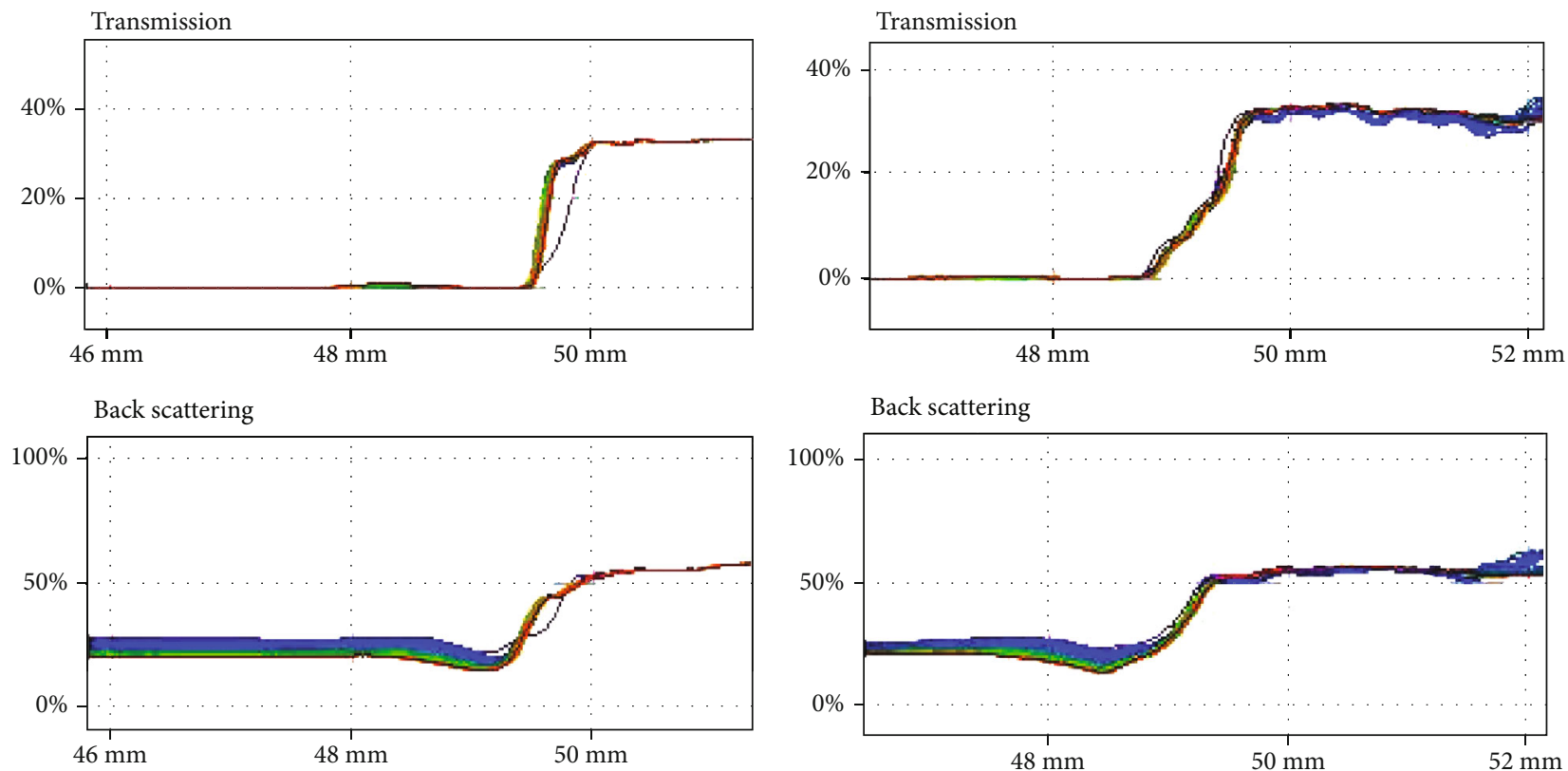

(c) Slurry $+0.2 \%$ HTRTP

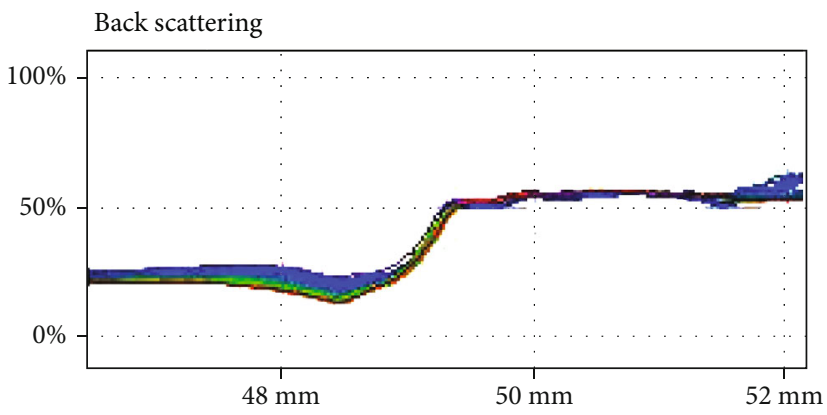

(d) Slurry + 0.3\%HTRTP

FIGURE 10: Effect of HTRTP on colloid stability of bentonite grouting (after aging).

of HTRTP reducing filter cake permeability by improving particle size grading in the system and enhancing the compressibility of filter cake is more important.

The action mechanism of high-temperature-resistant quaternary copolymer HTRTP is as follows:

(1) Temperature resistance mechanism: the molecular structure difference is the main factor that determines the temperature resistance of the fluid loss agent. High-temperature-resistance quaternary copolymer HTRTP molecule main chain is C-C bond and has the internal structure of high temperature resistance; $\mathrm{C}-\mathrm{S}$ and $\mathrm{C}-\mathrm{N}$ bonds are used between the main chain and the side chain, and the thermal stability of the main chain and the side chain is strong

(2) Mechanism of salt resistance and calcium resistance: the hydrophilic group is the sulfonic acid group $\left(-\mathrm{CH} 2 \mathrm{SO}_{3}{ }^{-}\right)$, which has strong hydration ability and can thicken the hydration film on the surface of clay particles with strong salt resistance. The sulfonic acid group does not react with $\mathrm{Ca}^{2+}$ to form precipitation, which has a strong anticalcium ability. In addition, the side groups introduced into the HTRTP chain (e.g., - $\left.\mathrm{CONHC}\left(\mathrm{CH}_{3}\right)_{2} \mathrm{CH}_{2} \mathrm{SO}_{3}{ }^{-}\right)$are large and rigid, and the chain is not easy to curl in electrolyte solutions (salt solutions) 
(3) Adsorption mechanism: in addition to the phthalamine group (-CON $\left.\left(\mathrm{CH}_{2} \mathrm{CH}_{3}\right)_{2}\right)$, the cationic adsorption group $\left(-\mathrm{CH}_{2} \mathrm{~N}^{+}\left(\mathrm{CH}_{3}\right)_{2} \mathrm{CH}_{2}-\right)$ is also introduced into the HTRTP molecular chain. $-\mathrm{CON}\left(\mathrm{CH}_{2} \mathrm{CH}_{3}\right)_{2}$ is adsorbed by hydrogen bond, which has strong adsorption stability and is not easy to be desorbed under temperature change. $-\mathrm{CH}_{2} \mathrm{~N}^{+}\left(\mathrm{CH}_{3}\right)_{2} \mathrm{CH}_{2}$ - is chemisorbed through static ion bonds, and the adsorption is stronger

(4) Mechanism of filtration loss reduction: firstly, HTRTP is adsorbed on the surface of clay particles to form an adsorption layer, which prevents flocculation of clay particles from becoming larger. At the same time, it stabilizes the fine particles separated by stirring so as not to become larger. So it can improve clay particle grading in drilling fluid. It has excellent protective adhesive effect, forming thin and compact filter cake, reducing filtration loss. Secondly, HTRTP increases the degree of hydration by adsorbing on clay particles, so that the hydration film on the surface of clay particles is thickened to enhance the compressibility of the filter cake and reduce the permeability of the filter cake, thus reducing the filtration loss. Thirdly, the molecular size of HTRTP is just within the range of colloidal particles, and the molecular chain wedges into the pores of the filter cake or curls into a ball to block the micropores of the filter cake, making the filter cake thin and compact, thus reducing the filtration loss. Finally, HTRTP is a high molecular weight polymer that is added to the drilling fluid to increase the viscosity of the filtrate and thus reduce filtration loss

\section{Conclusions}

The high-temperature-resistant quaternary copolymer HTRTP was synthesized by molecular structure optimization and monomer optimization. The viscosity average molecular weight of HTRTP was about 1 million, which had less effect on the viscosity of drilling fluid than DCL-a. HTRTP molecular structure has good thermal stability, temperature resistance in drilling fluid up to $245^{\circ} \mathrm{C}$, salt resistance and calcium resistance, and good compatibility with fresh water and salt water experimental base slurry. The performance of fluid loss reduction, temperature resistance and salt and calcium resistance in drilling fluid is better than that of foreign temperature resistance polymer DCL-a and domestic similar products. The adsorption capacity of HTRTP on clay particles is higher than that of foreign antitemperature polymer DCL-a. In the case of chemical environment and temperature change, the adsorption amount changed little and was still higher than that of DCL-a, and the adsorption was firm. Before and after aging $\left(245^{\circ} \mathrm{C} / 16 \mathrm{~h}\right)$, HTRTP can significantly reduce the permeability and improve the compressibility of filter cake. Improving the particle size grading in drilling fluid system and enhancing the colloidal stability of the system are the important mechanisms of high-temperature-resistant qua- ternary copolymers. The quad-element polymer reducer was suitable for fresh water-based drilling fluid and lowmineralized saline drilling fluid.

\section{Nomenclature}

AMPS: $\quad$ 2-Acry-lamido-2-methyl-1-propane sulfonic acid

API: American Petroleum Institute

AV: $\quad$ Apparent viscosity

DEAM: $\quad$ N, N-Diethyl acrylamide

DMDAAC: Dimethyl diallyl ammonium chloride

FT-IR: $\quad$ Fourier transform infrared spectroscopy

NVP: $\quad$ N-Vinyl pyrrolidone

PV: $\quad$ Plastic viscosity

TGA: Thermogravimetric analysis

YP: Dynamic shear forces.

\section{Data Availability}

All data and research results are listed in the manuscript.

\section{Conflicts of Interest}

The authors declare that they have no conflicts of interest.

\section{Acknowledgments}

This work was financially supported by the Open Foundation of State Key Laboratory of Oil and Gas Geology and Exploitation, Chengdu University of Technology (PLC20180103), and Opening Project of Oil and Gas Field Applied Chemistry Key Laboratory of Sichuan Province (YQKF202010).

\section{References}

[1] A. R. Ismail, W. R. Wan Sulaiman, M. Z. Jaafar, I. Ismail, and E. Sabu Hera, "Nanoparticles performance as fluid loss additives in water based drilling fluids," Materials Science Forum, vol. 864, no. 1, pp. 189-193, 2016.

[2] A. Nasiri, M. J. AMERI Shahrabi, M. A. Sharif NIK, H. Heidari, and M. Valizadeh, "Influence of monoethanolamine on thermal stability of starch in water based drilling fluid system," Petroleum Exploration and Development, vol. 45, no. 1, pp. 167-171, 2018.

[3] H. Zhong, G. Shen, Z. Qiu et al., "Minimizing the HTHP filtration loss of oil-based drilling fluid with swellable polymer microspheres," Journal of Petroleum Science and Engineering, vol. 172, pp. 411-424, 2019.

[4] X. Ma, M. Yang, and M. Zhang, "Synthesis and properties of a betaine type copolymer filtrate reducer," Chemical Engineering and Processing-Process Intensification, vol. 153, article 107953, 2020.

[5] F. Dugonjic-Bilic and J. Plank, "Polyelectrolyte complexes from polyethylene imine/acetone formaldehyde sulfite polycondensates: a novel reagent for effective fluid loss control of oil well cement slurries," Journal of Applied Polymer Science, vol. 121, no. 3, pp. 1262-1275, 2011. 
[6] X. Yang and Z. Wang, "Molecular design of polymer treatment agent used for drilling fluid," Fine and Specialty Chemicals, vol. 18, pp. 14-18, 2010.

[7] Z. Y. Chang, D. L. Breeden, and M. J. Mcdonald, "The use of zinc dialkyl dithiophosphate as a lubricant enhancer for drilling fluids particularly silicate-based drilling fluids," in SPE International Symposium on Oil Field Chemistry, The Woodlands, Texas, USA, 2011.

[8] X. Bai, Y. Yang, D. Xiao, X. Pu, and X. Wang, "Synthesis, characterization, and performance evaluation of the AM/AMPS/DMDAAC/SSS quadripolymer as a fluid loss additive for water-based drilling fluid," Journal of Applied Polymer Science, vol. 132, no. 14, article 41762, 2015.

[9] J. Su, Q. Chu, and M. Ren, "Properties of high temperature resistance and salt tolerance drilling fluids incorporating acrylamide/2-acrylamido-2-methyl-1-propane sulfonic acid/Nvinylpyrrolidone/dimethyl diallyl ammonium chloride quadripolymer as fluid loss additives," Journal of Polymer Engineering, vol. 34, no. 2, pp. 153-159, 2014.

[10] P. W. Livanec, G. P. Perez, and J. P. Deville, "Methods of preventing emulsification of crude oil in well bore treatment fluids," 2012, U.S. Patent No. 9,051,508.

[11] J. B. Wen, H. J. Luo, and Z. Q. Long, "Emulsification behaviors of crude oil-water system and its quantitative relationship with exergy loss rate," Journal of Petroleum Science \& Engineering, vol. 176, pp. 502-508, 2019.

[12] X. I. N. Haipeng, Z. E. N. G. Jianguo, Z. O. U. Jianlong, Z. H. A. O. Baohui, and S. U. N. Fuquan, "Laboratory study on comblike polycarboxylic acid friction reducer," Drilling Fluid and Completion Fluid, vol. 34, pp. 72-76, 2017.

[13] G. Duan, G. Huang, A. Li, Y. Zhu, and Y. Gong, "A study of supermolecular polarization of comb-like polycarboxylate admixtures synthesized with polyoxyethylene macromolecules," Journal of Molecular Liquids, vol. 174, pp. 129-134, 2012.

[14] Q. Jiang, G. Jiang, C. Wang et al., "A new high-temperature shear-tolerant supramolecular viscoelastic fracturing fluid," in IADC/SPE Asia Pacific Drilling Technology Conference, Singapore, 2016.

[15] W. Li, J. Liu, X. Zhao et al., "Development and screening of additives for biodiesel based drilling fluids: principles, strategies and experience (Conference Paper)," in Proceedings-SPE International Symposium on Oilfield Chemistry, Texas, USA, 2019.

[16] J. O. Oseh, M. N. A. Mohd Norddin, I. Ismail, A. O. Gbadamosi, A. Agi, and H. N. Mohammed, "A novel approach to enhance rheological and filtration properties of water- based mud using polypropylene-silica nanocomposite," Journal of Petroleum Science and Engineering, vol. 181, article 106264, 2019.

[17] X. F. Chang, J. S. Sun, Z. Xu et al., "Synthesis of a novel environment-friendly filtration reducer and its application in water-based drilling fluids," Colloids and Surfaces A: Physicochemical and Engineering Aspects, vol. 568, pp. 284-293, 2019.

[18] X. Liu, B. Xie, Y. Gao et al., "Development of low toxicity and high temperature polymer drilling fluid for environmentally sensitive offshore drilling," in IADC/SPE Asia Pacific Drilling Technology Conference and Exhibition, Bangkok, Thailand, 2018.

[19] L. Long, X. Xianguang, Z. Jinzhi et al., “Application of innovative high-temperature high-density oil-based drilling fluid technology in the efficient exploration and development of ultra-deep natural gas resources in West China," in International Petroleum Technology Conference, Bangkok, Thailand, 2016.

[20] H. Shen, K. Lv, X. Huang et al., "Hydrophobic ssociated polymer-based laponite nanolayered silicate composite as filtrate reducer for water-based drilling fluid at high temperature," Journal of Applied Polymer Science, vol. 137, no. 5, 2020.

[21] D. V. Kosynkin, G. Ceriotti, K. C. Wilson et al., "Graphene oxide as a high-performance fluid-loss-control additive in water-based drilling fluids," ACS Applied Materials and Interfaces, vol. 4, no. 1, pp. 222-227, 2012.

[22] H. Shen, K. Lv, X. Huang et al., "Hydrophobic-associated polymer-based laponite nanolayered silicate composite as filtrate reducer for water-based drilling fluid at high temperature," Journal of Applied Polymer Science, vol. 137, no. 18, article 48608, 2020.

[23] H. A. Craddock, "Oilfield chemistry and its environmental impact," John Wiley \& Sons, pp. 21-110, 2018.

[24] G. Pan, J. Chen, C. Zhang et al., "Combined technology of weak gel flooding assisting thermal huff and puff enhances oil recovery for offshore heavy oil field," in SPE Annual Technical Conference and Exhibition, Dubai, UAE, 2016.

[25] M. X. Li, S. C. Xie, H. Zhang, X. G. Wang, and Q. Z. Jin, "Effect of mechanical stirring rate on the texture, rheological property and microstructure of gel-like oil," Journal of Food Science and Biotechnology, vol. 32, pp. 393-398, 2013.

[26] R. Jain, T. K. Mahto, and V. Mahto, "Rheological investigations of water based drilling fluid system developed using synthesized nanocomposite," Korea Australia Rheology Journal, vol. 28, no. 1, pp. 55-65, 2016.

[27] K. K. Chandan and G. P. Karmakar, "Drilling fluid waste treatment using polysaccharide-grafted copolymers," The APPEA Journal, vol. 59, no. 1, pp. 34-46, 2019.

[28] P. Dejtaradon, H. Hamidi, M. H. Chuks, D. Wilkinson, and R. Rafati, "Impact of $\mathrm{ZnO}$ and $\mathrm{CuO}$ nanoparticles on the rheological and filtration properties of water-based drilling fluid," Colloids and Surfaces A: Physicochemical and Engineering Aspects, vol. 570, pp. 354-367, 2019.

[29] B. Xie, X. Zhang, Y. Li, W. Liu, and M. Luo, “Application a novel thermo-sensitive copolymer as a potential rheological modifier for deepwater water-based drilling fluids," Colloids and Surfaces A: Physicochemical and Engineering Aspects, vol. 581, article 123848, 2019. 